\title{
IMPORTÂNCIA DA DISSEMINAÇÃO DO ENSINO DO BIM NAS UNIVERSIDADES E IMPLEMENTAÇÃO DENTRO DE CONSTRUTORAS PARA FORMAÇÃO DE BIM MANAGERS
}

Ródney Silvério Costa Junior; Giuliano Mikael Tonelo Pincerato.

Centro Universitário Católico Salesiano Auxilium - Unisalesiano, Aluno de Engenharia Civil, Araçatuba, SP. E-mail: juniorcivil.sale@hotmail.com.

\section{RESUMO}

Uma metodologia inovadora que está crescendo no país é o conceito BIM, o qual envolve integração de softwares e profissionais, promovendo uma gestão de obras de forma otimizada e precisa. Este artigo tem como objetivo explicitar a ausência do ensino do BIM dentro das universidades, a não utilização destas ferramentas em construtoras, por fim a falta de conhecimento, de alunos e profissionais do ramo, da existência desta tecnologia. Os resultados coletados através de revisão bibliográfica e coleta de dados in loco mostraram que há necessidade de maior difusão desta metodologia para uma aplicação prática satisfatória. Concluímos que, a importância do ensino e implementação do BIM é relevante e necessária, não só para criação de novas profissões como, por exemplo, a de gerente BIM, mas também para uma maior integração e relação empreendedora entre universidade e empresa, garantindo qualificação de profissionais e eficiência quanto a lucro e gestão dentro das corporações.

Palavras-chave: tecnologia BIM, Modelagem da Informação da Construção, integração universidade-empresa, gestão de obra, gerente BIM.

\section{IMPORTANCE OF THE DISSEMINATION OF BIM TEACHING IN UNIVERSITIES AND IMPLEMENTATION WITHIN CONSTRUCTION COMPANIES FOR FORMATION OF BIM MANAGERS}

\begin{abstract}
An innovative methodology that is growing in the country is the BIM concept, which involves integration of software and professionals, promoting an optimized and precise management of buildings. This article aims to explain the lack of teaching of BIM within universities, as well as the lack of use of these tools in constructors, and finally the lack of knowledge of students and professionals in the industry, of the existence of this technology. The results collected through bibliographic review and face-to-face questionnaires showed that there is a need for greater dissemination of this methodology for a satisfactory practical application. We conclude that the importance of teaching and implementing BIM is relevant and necessary, not only for the creation of new professions such as the BIM manager, but also for a greater integration and entrepreneurial relationship between university and company, guaranteeing the qualification of professionals and profitability and management within corporations.
\end{abstract}

Keywords: BIM technology, Building Information Modelling, university-company integration, construction management, BIM Manager. 


\section{INTRODUÇÃO}

A necessidade de atualização às inovações tecnológicas está cada vez mais essencial ao mercado de trabalho assim como ao ambiente acadêmico. Novas formas de produzir, trabalhar e projetar estão dia após dia mudando paradigmas, antes tradicionais e de certa forma dogmáticos, para maneiras inovadoras, altamente integradas, multidisciplinares e cada vez mais globalizadas.

$\mathrm{Na}$ engenharia civil, estas inovações acontecem de forma acelerada e contínua, requerendo uma qualificação periódica dos profissionais envolvidos tanto na parte teórica quanto na parte prática, ou seja, as universidades e empresas devem-se manter atentas às novas descobertas e otimizações das práticas construtivas, para garantir sempre o melhor resultado não só quantitativo (lucro) quanto qualitativo (qualificação).

Uma alternativa para que se possa ser adotada garantindo a qualificação de alunos e incorporação deste futuro profissional dentro de grandes empresas do ramo, seria uma aproximação da relação no caso de construtoras/incorporadoras com universidades, possibilitando assim um espírito de empreendedorismo, desenvolvimento de competências pessoais e profissionais, qualificação da futura mão-de-obra, entre outros fatores importantes a serem levados em consideração.

Segundo Dolabela (2003), é somente a inovação que vai lhe permitir iniciar e desenvolver uma caminhada empreendedora, assim configurando-se no momento em que um sonho ou ideia se torna realidade. Para o autor, empreender não seria apenas construção de novos produtos e processos, mas sim, significa inicialmente a modificação do contexto real, sendo por fim um processo de construção do futuro.

Uma inovação dentro desta grande área que aos poucos vem crescendo e se difundindo no país é a metodologia BIM (em português, modelagem da informação da construção). Até então, os projetos civis são feitos de forma separada entre as frentes de serviço, ou seja, de forma não integrada e só será compatibilizada em campo dentro de canteiros de obras. Segundo Bernardes (2003), planejamento pode ser considerado a definição de um futuro desejado e de meios eficazes de alcançá-lo. Portanto, tal tecnologia tem como principal atividade, a integração de softwares, profissionais e informações, garantindo uma gestão de obra otimizada com o ciclo de vida da edificação dominado, através de modelagens arquitetônicas paramétricas precisas e planejamento com cronogramas físico-financeiros detalhados e reais. Todo esse banco de dados valiosos evitam assim, retrabalhos futuros causados por interferências e incompatibilidades de projeto explicitadas nos canteiros de obra, durante a execução destas construções.

Esta tecnologia na Europa e América do Norte já não é uma novidade assim como é no Brasil. Estamos em fase inicial para total implementação organizacional desta atividade em construtoras e nos ambientes universitários, ou seja, não há conhecimento e qualificação em grande parte das instituições e corporações, e quando há algum tipo de projeto envolvendo BIM, é de forma embrionária, sem aproveitar todas as vantagens provindas desta metodologia.

Portanto, para certificar de que este cenário é uma realidade na engenharia civil, o presente artigo teve como objetivo coletar informações através de uma pesquisa envolvendo construtoras e universidades da cidade de Araçatuba.

Será também diagnosticado dentro da universidade Unisalesiano nas salas de aula do curso de Engenharia Civil e Arquitetura, através de uma pesquisa de campo com alunos feita com perguntas, se os discentes possuem conhecimento da existência deste método de gerenciar obras e projetos ou se até os mesmos já estão se qualificando nesta área de atuação, podendo ser possível explicitar a potencialidade atual de existência de novos BIM Managers no mercado de trabalho Araçatubense (em português gerentes BIM).

Por fim, será discorrida superficialmente a importância e as vantagens da utilização desta tecnologia nos mercados de trabalho e ambientes acadêmicos, possibilitando uma relação empreendedora entre os envolvidos a partir dos benefícios gerados com a implementação do BIM, 
uma vez que as relações e serviços se tornam cada vez mais integradas (comunicação entre as partes envolvidas e interessadas muito mais eficiente), eficazes (possibilidade de resolução de grandes problemas que antes seriam encontrados apenas no canteiro de obras causando retrabalhos) e lucrativas (pois há uma gestão mais dominada de recursos, prazo e interferências já na etapa de projeto).

\section{METODOLOGIA}

Segundo Eastman (2011), a integração não só de profissionais, mas também de dados paramétricos e de projeto, seria a chave para uma melhor gestão dos processos, práticas construtivas, insumos e pessoas. Eastman em seu guia sobre BIM exemplifica casos reais da utilização da metodologia BIM nas construtoras e incorporadoras e os resultados são sempre satisfatórios. A possibilidade de um maior domínio das atividades e do ciclo de vida das edificações, maior facilidade de visualização de incompatibilidades e maior controle de prazo e quantitativos, acarreta lucros através da diminuição de retrabalhos e otimização dos processos construtivos devido a alta quantidade de parâmetros utilizados nos projetos e alto domínio dessas informações.

No entanto, em nosso país, o processo de aplicação desta metodologia na prática tanto nas empresas quanto na qualificação de estudantes universitários e profissionais, está ocorrendo de forma lenta, porém gradual. No ano de 2016, a CBIC (Câmara Brasileira da Indústria da Construção), promoveu várias palestras, workshops, encontros e fóruns de discussões sobre o tema com os melhores profissionais da área em vários locais do país, e tais atividades tiveram como fruto uma coletânea que serve como um guia para implementação do BIM nas construtoras produzido pelo renomado engenheiro civil Wilson Catelani, um dos principais relatores e analistas da primeira norma técnica brasileira sobre BIM que está em processo de desenvolvimento (NBR 15965). Catelani (2016) salientou fortemente que dentro de poucos anos o BIM será exigido por prefeituras e clientes, ou seja, as vantagens são tantas que em um futuro próximo o BIM deixará de ser opção para condição primordial para se trabalhar na indústria da construção.

Na América Latina, o Chile já está utilizando em seus projetos o BIM e está a frente do Brasil na frequência de uso desta tecnologia, conforme explicitado pelo empresário chileno Juan Carlos Del Río em um fórum chamado ENIC (Encontro Nacional da Indústria da Construção) promovido pelo CBIC. O chileno destacou que houve um grande ganho de produtividade em sua empresa embora em um primeiro momento a implementação foi difícil e com um custo alto, portanto o uso do BIM requer investimentos porém a médio prazo já é muito rentável.

Portanto, este trabalho trata-se de uma coleta de dados através de um levantamento na cidade de Araçatuba, curta porém diagnóstica, a fim de saber se os alunos de universidade do curso de Engenharia Civil da instituição Unisalesiano possuem no mínimo, conhecimento e consciência de existência desta tecnologia. Se sim, há quanto tempo conhece e/ou se já a utiliza na prática ou em cursos de qualificação. Da mesma forma foi feito um apontamento, se construtoras utilizam esta tecnologia para benefícios da corporação.

Foi levantada também a questão dentro destes assuntos tratados se os alunos universitários entendem como importante a relação próxima entre faculdades e empresas a fim de criar vínculos capazes de desenvolver competências, valores e qualificações, as quais só são possíveis através de práticas, cursos e situações reais de campo.

No próximo tópico serão explicitados os dados coletados em campo, através de tabelas que serão posteriormente discutidas durante o trabalho.

\section{RESULTADOS}

Foi feito um levantamento através de contato direto com as construtoras a fim de analisar se as mesmas já estão utilizando dentro de seus escritórios e obras a tecnologia BIM, assim como 
se há conhecimento da existência dessa maneira de construir e gerenciar edificações. Os resultado obtido é explicitado na tabela 1 abaixo:

Tabela 1. Pesquisa da utilização da tecnologia BIM nas construtoras de Araçatuba

\begin{tabular}{|l|l|}
\hline $\begin{array}{l}\text { Principais Construtoras/ Incorporadoras } \\
\text { presentes na cidade de Araçatuba }\end{array}$ & $\begin{array}{l}\text { A empresa utiliza } \\
\text { obras? }\end{array}$ \\
\hline RB Engenharia e Construções LTDA & Não \\
Constroen Construções e Engenharia LTDA & Não \\
Ferreira Engenharia e Construções LTDA & Não \\
MRV Engenharia e Participações S.A & Não \\
Lomy Engenharia LTDA & Não \\
Conscape Construções e Engenharia LTDA & Não \\
Adriano Afonso Empreendimentos LTDA & Não \\
\hline
\end{tabular}

Fonte: Próprio Autor

Em seguida, foi feita uma pesquisa de amostragem voluntária conforme mostra a tabela 2, com alunos dos cursos de Engenharia e Arquitetura, para diagnosticar o nível de conhecimento e a quantidade de alunos que possuem a consciência da existência da tecnologia BIM. Caso não conheçam, se ao menos já ouviram falar no software de modelagem arquitetônica BIM mais conhecido e utilizado no momento (Auto Desk Revit) e no software de planejamento MS Project. Por fim é despertada na pesquisa, a questão da importância, que os alunos consideram na proximidade de relações entre universidades e empresas, a fim de desenvolver competências empreendedoras, qualificatórias e práticas. 
Tabela 2. Pesquisa do conhecimento da Tecnologia BIM na universidade Unisalesiano de Araçatuba

\begin{tabular}{|c|c|c|c|c|c|}
\hline Perguntas & $\begin{array}{c}\text { Engenharia } \\
\text { Civil 8o } \\
\text { Termo } \\
\text { Total: } \\
61 \text { alunos }\end{array}$ & $\begin{array}{l}\text { Engenharia } \\
\text { Civil 10o } \\
\text { Termo } \\
\text { Total: } \\
59 \text { alunos }\end{array}$ & $\begin{array}{l}\text { Engenharia } \\
\text { Civil 40 } \\
\text { Termo } \\
\text { Total: } \\
44 \text { alunos }\end{array}$ & $\begin{array}{l}\text { Engenharia } \\
\text { Civil 2o } \\
\text { Termo } \\
\text { Total: } \\
40 \text { alunos }\end{array}$ & $\begin{array}{l}\text { Arquitetura } \\
\text { 20 Termo } \\
\\
\text { Total: } \\
47 \text { alunos }\end{array}$ \\
\hline $\begin{array}{lr}\text { Quantidade } & \text { de } \\
\text { alunos } & \text { que } \\
\text { conhecem ou ao } \\
\text { menos já ouviram } \\
\text { falar da tecnologia } \\
\text { BIM. }\end{array}$ & $\begin{array}{c}8 \\
\text { alunos }\end{array}$ & $\begin{array}{l}9 \\
\text { alunos }\end{array}$ & $\begin{array}{c}1 \\
\text { aluno }\end{array}$ & $\begin{array}{l}\text { Nenhum } \\
\text { aluno. }\end{array}$ & $\begin{array}{c}1 \\
\text { aluno }\end{array}$ \\
\hline $\begin{array}{l}\text { Se sim, como } \\
\text { conheceram? }\end{array}$ & Internet & Internet & Curso & 0 & Internet \\
\hline $\begin{array}{lr}\text { Dos que } & \text { não } \\
\text { conhecem } & \text { a } \\
\text { Tecnologia } & \text { BIM, } \\
\text { quantos já } & \text { ouviram } \\
\text { falar no software } \\
\text { Revit? }\end{array}$ & $\begin{array}{l}19 \\
\text { alunos }\end{array}$ & $\begin{array}{l}23 \\
\text { alunos }\end{array}$ & $\begin{array}{l}28 \\
\text { alunos }\end{array}$ & $\begin{array}{c}7 \\
\text { alunos }\end{array}$ & $\begin{array}{l}31 \\
\text { alunos }\end{array}$ \\
\hline $\begin{array}{lr}\text { Dos que não } \\
\text { conhecem a } \\
\text { Tecnologia BIM, } \\
\text { quantos já ouviram } \\
\text { falar no software } \\
\text { MS Project? }\end{array}$ & $\begin{array}{c}2 \\
\text { alunos }\end{array}$ & $\begin{array}{c}11 \\
\text { alunos }\end{array}$ & $\begin{array}{l}\text { Nenhum } \\
\text { aluno }\end{array}$ & $\begin{array}{l}\text { Nenhum } \\
\text { aluno }\end{array}$ & $\begin{array}{c}2 \\
\text { alunos }\end{array}$ \\
\hline 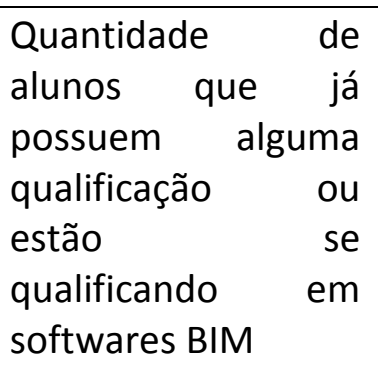 & $\begin{array}{c}1 \\
\text { aluno }\end{array}$ & $\begin{array}{c}8 \\
\text { alunos }\end{array}$ & $\begin{array}{l}\text { Nenhum } \\
\text { aluno }\end{array}$ & $\begin{array}{c}1 \\
\text { aluno }\end{array}$ & $\begin{array}{l}\text { Nenhum } \\
\text { aluno }\end{array}$ \\
\hline $\begin{array}{lr}\begin{array}{l}\text { Quantidade } \\
\text { alunos de } \\
\text { consideram } \\
\text { importante }\end{array} \\
\text { existência de uma } \\
\text { relação próxima } \\
\text { entre universidade e } \\
\text { empresas para } \\
\text { desenvolvendo de } \\
\text { competências. }\end{array}$ & $\begin{array}{l}37 \\
\text { alunos }\end{array}$ & $\begin{array}{l}34 \\
\text { alunos }\end{array}$ & $\begin{array}{c}44 \text { alunos } \\
\text { (Todos da } \\
\text { sala) }\end{array}$ & $\begin{array}{l}33 \\
\text { alunos }\end{array}$ & $\begin{array}{c}21 \\
\text { alunos }\end{array}$ \\
\hline
\end{tabular}


Já na tabela 3, foi feita um apontamento se nas três principais universidades presentes na cidade de Araçatuba, já há dentro das grades curriculares o ensino ou se ao menos existe a disponibilidade de cursos optativos relacionados a metodologia BIM e/ou de softwares que integram tal conceito.

Tabela 3. Pesquisa sobre a presença do ensino do BIM nas principais universidades de Araçatuba

\begin{tabular}{|l|c|}
\hline \multicolumn{1}{|c|}{ Universidades de Araçatuba } & $\begin{array}{c}\text { Possuem ensino na grade ou cursos optativos } \\
\text { de softwares BIM e metodologia BIM? }\end{array}$ \\
\hline$\underline{\text { Unisalesiano }}$ & Não \\
\hline$\underline{\text { UNIP }}$ & $\begin{array}{c}\text { Ensino do software Revit para cursos de } \\
\text { Arquitetura }\end{array}$ \\
\hline$\underline{\text { Unitoledo }}$ & Não \\
\hline
\end{tabular}

Fonte: Próprio Autor

\section{DISCUSSÃO}

Foi constatado, conforme explicitado na tabela 1, que em $100 \%$ das principais construtoras existentes em Araçatuba não possuem essa tecnologia implementada. Todas elas alegaram não possuí-la na empresa, por não verem a necessidade de implantação uma vez que estão habituados com a forma de planejar, construir e gerenciar as obras ou por falta de conhecimento de todas as funcionalidades e benefícios provindos do uso do BIM. Portanto, conclui-se que primeiramente falta na verdade uma maior difusão da tecnologia BIM e as vantagens da sua utilização. Outro fator que pode ser citado seria a falta de ambição para se investir numa tecnologia nova que até então não está consolidada nas construções civis justamente por falta de qualificação de profissionais e difusão desta metodologia.

A pesquisa feita referente a tabela 2 foi de grande valia e muito interessante pois foi possível perceber a reação dos alunos participantes da amostra voluntária. Pôde-se notar que há uma enorme falta de informação referente a tecnologia BIM, ou seja, esse conceito ainda é bastante incipiente dentro da universidade. Através dos dados coletados, foi possível verificar um maior conhecimento nas turmas que estão prestes a se formar como é o caso do 10 termo de engenharia civil, fato oposto nos termos que estão iniciando o curso (2 termo de engenharia civil). No entanto uma conclusão unânime entre todos os períodos participantes da pesquisa é de que a maioria dos alunos consideram de extrema valia e importância a relação mais próxima entre universidades e empresas.

Por fim na tabela 3, nas três principais universidades de Araçatuba constatou-se que apenas no curso de Arquitetura da Universidade Paulista(UNIP) é lecionado no mínimo o software de modelagem arquitetônica da Auto Desk, o Revit Architeture.

\section{CONCLUSÃO}

A criação da profissão BIM Manager atualmente no Brasil, em especial no interior do estado conforme pesquisado por este artigo, parece ainda estar a um passo distante de se popularizar. No entanto, este não é um revés, e sim uma oportunidade de emprego que se com uma boa qualificação, há a possibilidade de ingresso no mercado de trabalho da engenharia civil com um bom panorama de progresso e remuneração, uma vez que a tecnologia só tende a crescer e consolidar na área de construção conforme previsto por Catelani (2016).

Para isso, as construtoras e universidades devem ter uma relação mais próxima, com uma característica pedagógica e empreendedora incentivada por Dolabela (1999;2003). E tal fato é de interesse de alunos que estão dentro das Universidades. Basta investimentos em cursos de 
capacitação, práticas de campo e contextualização do aprendizado teórico com o dia-a-dia da profissão na realidade, sendo possível desenvolvimento de competências importantes que apenas dentro de salas de aula, não são possível adquiri-las; e tudo isso antes da inserção no mercado de trabalho. Com isso, o aluno será visto com bons olhos pelas empresas, ou seja, gerará uma maior concorrência por aquele aluno recém-formado que obteve experiências diferenciadas de aplicação teórica na prática, assim como cursos qualificatórios na área de atuação, sendo algo produtivo e vantajoso para ambos os envolvidos.

Por fim, para resultados satisfatórios e otimizados dentro do ramo de construções, é de extrema importância a difusão do conceito BIM tanto nas universidades quanto nas construtoras conforme foi verificado no estudo feito neste artigo. A qualidade gerada na gestão das edificações através de sua utilização é de grande valia, portanto devem ser feitos investimentos tanto em capital humano quanto tecnológico, ou seja, valorização do profissional, do aluno e da inovação; mudança de paradigma do que é feito atualmente na construção civil, ou seja, renúncia parcial aos softwares habituais, práticas construtivas e modelos de gestão que não são totalmente eficazes; finalmente, valorização das relações empreendedoras entre universidades e empresas, uma vez que quanto mais profissionais qualificados, mais concorrência haverá, consequentemente mais progresso e qualidade haverá na criação de serviços e produtos disponíveis no mercado.

\section{REFERÊNCIAS}

BERNARDES, M. M. S. Planejamento e controle da produção para empresas de construção civil. Rio de Janeiro: LTC, 2003.

CATELANI, W.S. et al. Implementação do BIM para Construtoras e Incorporadoras. v.1 ao v.6. Brasília: CBIC, 2016.

DOLABELA, F. Oficina do empreendedor. São Paulo: Editora de Cultura, 1999.

DOLADELA, F. Pedagogia Empreendedora. São Paulo: Editora de Cultura, 2003.

EASTMAN, C. et al. Bim handbook: a guide to building information modeling for owners, managers, designers, engineers and contractors. 2 ed. New Jersey: John Wileys \& Sons, 2011. 